\title{
KAJIAN ELEMEN ARSITEKTUR CINA STUDI KASUS: BANGUNAN KLENTENG \\ DI KAWASAN PECINAN GLODOK
}

\author{
A study on Chinese Architectural Elements \\ Case Study: Temples in Glodok Chinatown Area
}

\section{Dian Monica Erveline Basri ${ }^{1}$, Andreas Nopratha Masieh ${ }^{2}$, Fadlika Bella Shafira ${ }^{3}$, Puji Astuti Sandora ${ }^{4}$}

Arsitektur, Tanri Abeng University

E-mail:monica.basri@tau.ac.id

\begin{abstract}
Abstrak
Hubungan Cina dan Indonesia telah terjalin sejak jaman kerajaan-kerajaan di Nusantara melalui kegiatan perdagangan yang dilakukan oleh kedua bangsa. Hal ini dibuktikan oleh pengaruh budaya yang dibawa oleh saudagar-saudagar Cina yang menetap di Nusantara. Salah satu pengaruh budaya tersebut dapat kita lihat pada arsitektur bangunan Tionghoa di Indonesia, utamanya pada bangunan klenteng. Klenteng-klenteng masyarakat Tionghoa di Indonesia telah ada sejak abad 16. Klenteng-klenteng yang bertahan sekarang telah mengalami berbagai peristiwa sejarah di masa lampau, sehingga bentuk arsitektur klenteng yang kita temukan sekarang telah berbeda dari bentuk arsitektur aslinya. Daerah dengan jumlah klenteng terbanyak yang dapat ditemukan di Jakarta terdapat di kawasan pecinan Glodok, oleh karenanya studi kasus diambil dari area tersebut. Penelitian ini bertujuan untuk mengidentifikasi dan menganalisa kecocokan elemen arsitektur bangunan klenteng yang terdapat di Glodok Jakarta Barat dengan elemen arsitektur Cina. Dari hasil penelitian dapat disimpulkan bahwa elemen arsitektur bangunan klenteng di Glodok memiliki kemiripan dengan elemen arsitektur Cina.
\end{abstract}

Kata kunci: elemen arsitektur, façade, klenteng, cina

\section{PENDAHULUAN}

Di Indonesia, bangunan peribadatan Tionghoa dikenal dengan beberapa istilah. "klenteng" sendiri merupakan istilah yang dikenal di pulau Jawa yang berasal dari deformasi kata Guan Ying Ting atau Rumah Ibadah Guan Yin ${ }^{1}$. Tapi menurut Ezerman kata "Kelenteng" atau "Klenteng" berasal dari suara lonceng yang terdengar ketika ada upacara². Klenteng pertama yang dibangun di Indonesia yaitu Klenteng Jin De Yuan atau Kim Tek Le

\footnotetext{
${ }^{1}$ Claudin Salmon dan Denys Lombard, Klentengklenteng dan masyarakat Tionghoa di Jakarta (Jakarta: Yayasan Cipta Loka Caraka, 2003), hal. 10.
}

terletak di Batavia dan dibangun pada tahun 1650. Klenteng ini dibangun sebagai tempat peribadatan umat Buddha Tionghoa di Batavia, lokasi klenteng sekarang berada di Kawasan pecinan Glodok, Jakarta Barat. Klenteng ini mengalami beberapa kali kebakaran, yaitu pada tahun 1740 ketika terjadi peristiwa

\footnotetext{
2 J. L. J. F. Ezerman, Peri Hal Kelenting Koan lem "Tiao-Kak-Sie" Di Tjirebon (Weltevreden: Drukkerij Volkslectuur, 1922), hal.
} 
pembantaian etnis Tionghoa ${ }^{3}$ dan kebakaran tahun 20154. Di kawasan pecinan Glodok terdapat beberapa bangunan klenteng yang dibangun pada abad 16 sampai dengan 19 yang juga tidak luput dari kerusakan akibat peristiwa sejarah dan mengalami pemugaran. Sehingga terjadi perubahan elemen-elemen arsitekturnya dari bangunan yang sebelumnya. Karena banyaknya perubahan yang terjadi pada bangunan klenteng di Jakarta, khususnya di kawasan pecinan Glodok, maka diperlukan identifikasi pada bangunan-bangunan klenteng tersebut agar dapat diketahui tipologi arsitekturnya.

\section{METODE}

Dalam penelitian ini, pertama-tama akan dibahas tinjauan tentang elemen-elemen arsitektur Cina. Kemudian dari studi kasus yang dipilih, masing masing elemen bangunannya akan dianalisa berdasarkan elemen elemen arsitektur Cina-nya. Kemudian akan disimpulkan seberapa banyak kecocokan elemen-elemen arsitektur studi kasus yang dipilih dengan elemen-elemen arsitektur Cina yang dijadikan landasan teori.

Variabel penelitian adalah bentuk visual, dengan indikator: bentuk atap, bentuk kolom dan balok, bentuk ornamen, bentuk dinding, bentuk tangga dan material, dengan indikator: material dan warna elemen arsitekturnya.

\section{LANDASAN TEORI ELEMEN-ELEMEN ARSITEKTUR TRADISIONAL CINA}

Sejarawan arsitektur Cina membagi bangunan tradisional Cina menjadi 3 elemen dan komponen utama, yaitu:

1. Podium atau lantai tingkat (tái ji 台基 dan 基 础jīchǔ)

2. Pilar dan struktur balok (柱梁 zhùliáng)

3. Atap melengkung (wūdǐng 屋顶) $)^{5}$

\footnotetext{
${ }^{3}$ Claudin Salmon dan Denys Lombard, Klentengklenteng dan masyarakat Tionghoa di Jakarta (Jakarta: Yayasan Cipta Loka Caraka, 2003), hal. 21. 4 Jakarta's historic Dharma Bhakti Temple gutted in overnight blaze, Jakarta Post, 2015-07-29
}

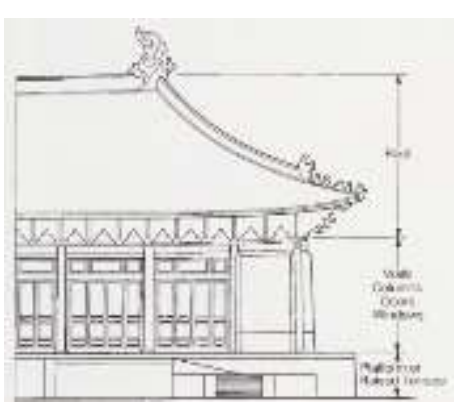

Gambar 1. Elemen bangunan tradisional Cina

(Sumber: Charis Chan, Imperial China, (London, Penguin Books, 1991)

\section{PODIUM DAN LANTAI}

Bangunan tradisional Cina umumnya dibangun diatas lantai keras yang terbuat dari tanah, batu atau bata yang dinaikan dari permukaan tanah. Dasar lantai ini berguna untuk menopang beban bangunan agar tidak terjadi deformasi bentuk ${ }^{6}$.

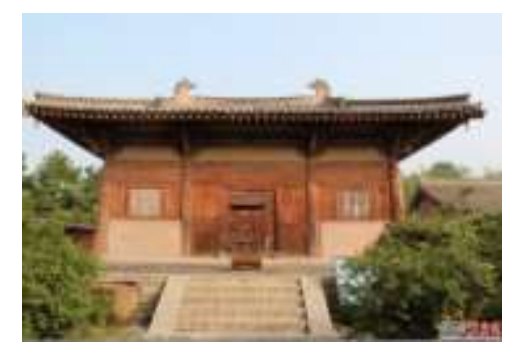

Gambar 2. Lantai batu pada bangunan tradisional Cina

(Sumber:

https://www.chinadaily.com.cn/m/shanxi/wutaish an/2015-01/08/content_19271797.htm)

\section{PILAR}

Kolom dan dinding biasanya dilapisi dan dicat dengan satu warna, seperti warna merah untuk bangunan kerajaan dan kuil, yang memberikan kesan sederhana yang kontras dengan dekorasi atap yang berwarna-warni. Hanya pola kisi-kisi pada pintu dan jendela yang memisahkan kesatuan antara dinding dan kolom. Pada kebanyakan bangunan, pilar terbuat dari batang kayu pohon pinus. Pilar biasanya akan ditempatkan diatas pedestal yang terbuat dari batu supaya tidak lapuk dan terkena rayap. Pada bangunan-bangunan

${ }^{5}$ Ronald G. Knapp, China's Old Dwellings, (Honolulu: University of Hawai'i Press, 2000), hal. 71.

${ }^{6}$ Ronald G. Knapp, China's Old Dwellings, (Honolulu: University of Hawai'i Press, 2000), hal. 72. 
besar, pedestal batu ini biasanya dihiasi oleh pahatan. Pahatan yang populer adalah pahatan berbentuk bunga teratai mekar yang diambil dari simbolisme agama Buddha. ${ }^{7}$

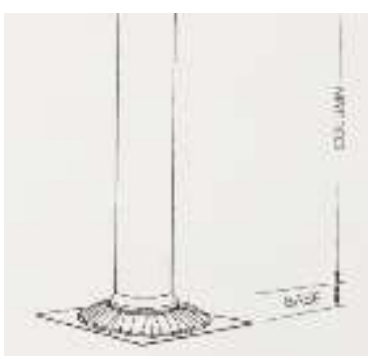

Gambar 3. Pilar dan pedestal

(Sumber: Charis Chan, Imperial China, (London, Penguin Books, 1991), 27.)

\section{DINDING}

Pada kebanyakan bangunan tradisional, semua beban atap ditopang oleh kolom-kolom kayu, bukan oleh dinding. Karena kolom yang menopang semua beban atap, maka perancang dapat dengan bebas menempatkan dinding, jendela dan pintu, sehingga sering dijumpai bangunan-bangunan besar memiliki dinding yang tipis dan ringan disertai dengan kisi-kisi motif. Di Cina bagian selatan di mana iklimnya panas dan lembap, sering kali sisi bangunan yang menghadap ke selatan dibiarkan terbuka atau diberikan bingkai kisikisi motif agar sirkulasi udara berjalan dengan baik. Sebaliknya, bangunan di Cina bagian utara yang memiliki iklim sub tropis, bangunan harus terlindungi dari dingin pada musim dingin dan harus memiliki sirkulasi udara yang baik ketika musim panas, maka digunakan pintu lipat yang dapat dibuka ketika musim panas. $^{8}$

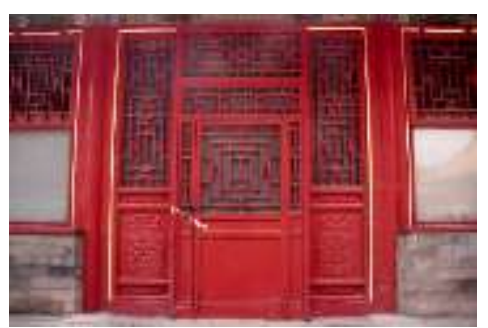

Gambar 4. Pintu dan dinding

\footnotetext{
${ }^{7}$ Charis Chan, Imperial China, (London, Penguin Books, 1991), hal. 37.

${ }^{8}$ Charis Chan, Imperial China, (London, Penguin Books, 1991), hal. 20.
}

(Sumber:

https://www.flickr.com/photos/sensaos/47908 27069/in/pool-15116517@N00/)

\section{ATAP \\ BENTUK ATAP}

Pada bangunan tradisional, perancang merencanakan bangunannya didasari oleh jarak antar kolom yang dibutuhkan pada bangunannya. Kemudian atap akan dirancang sesuai dengan panjang dan lebar bangunannya. Bentuk atap pada bangunan tradisional Cina dibagi ke dalam 5 jenis $^{9}$, yaitu:

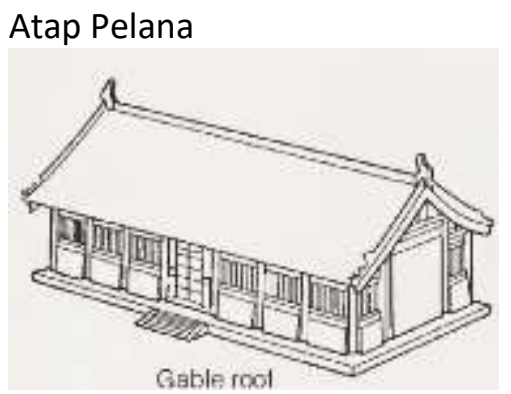

Gambar 5. Atap pelana

(Sumber: Charis Chan, Imperial China, (London, Penguin Books, 1991), 28.)

Atap Limasan

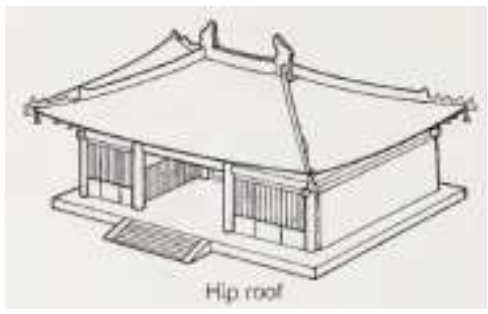

Gambar 6. Atap limasan

(Sumber: Charis Chan, Imperial China, (London, Penguin Books, 1991), 28.)

Atap Limas Pelana

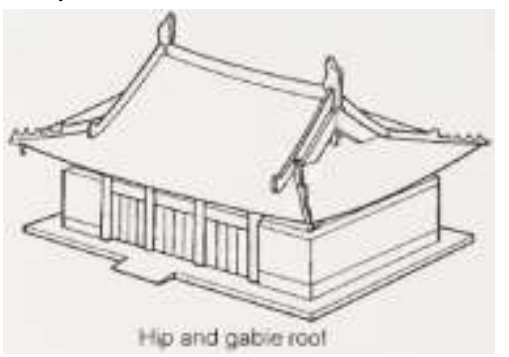

Gambar 7. Atap limas pelana

(Sumber: Charis Chan, Imperial China, (London, Penguin Books, 1991), 28.)

\footnotetext{
${ }^{9}$ Charis Chan, Imperial China, (London, Penguin Books, 1991), hal. 28.
} 
Atap Limasan Ganda

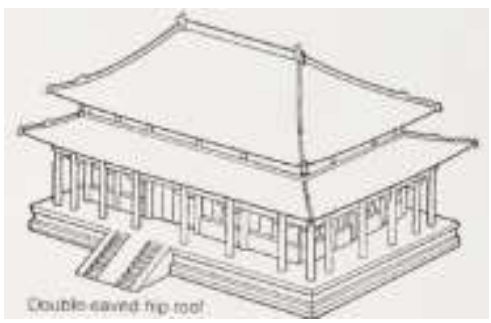

Gambar 8. Atap limasan ganda

(Sumber: Charis Chan, Imperial China, (London, Penguin Books, 1991), 28.)

Atap Tajug

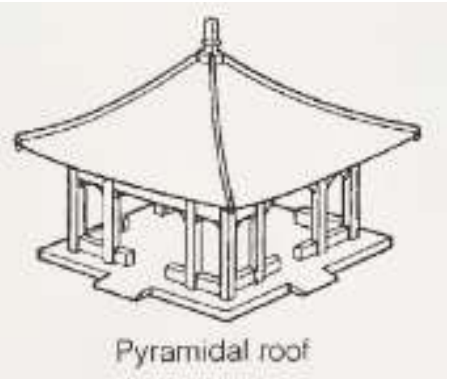

Gambar 9. Atap tajug

(Sumber: Charis Chan, Imperial China, (London, Penguin Books, 1991), 28.)

\section{GENTENG (琉璃瓦 liúlíwă)}

Genteng yang divernis adalah material yang berkelas tinggi pada bangunan jaman dahulu di Cina, yang hanya digunakan di bangunanbangunan istana, kuil dan bangunan pejabat tinggi negara. Warna genteng biasanya adalah kuning, hijau, biru dan hitam. Genteng yang dilapisi dengan warna tersebut bukan hanya memperindah bangunan, namun pada jaman dahulu juga menunjukkan status sosial penghuninya. Genteng berwarna kuning dikhususkan bagi bangunan istana kerajaan, makam, taman kerajaan dan kuil. Karena warna kuning disebut sebagai warna Sungai Kuning yang dipercaya sebagai tempat lahir peradaban bangsa Cina. Warna kuning merepresentasikan elemen tanah yang menjadi pusat alam semesta dan hanya boleh digunakan oleh penguasa. Warna hitam merepresentasikan elemen air dan genteng berwarna hitam diartikan sebagai air yang selalu siap untuk memadamkan api. Sementara warna biru merepresentasikan surga dan biasa ditemukan pada bangunan kuil. Pada bangunan kerajaan, warna genteng

\footnotetext{
${ }^{10}$ Du Feibao, Things Chinese, (China Travel \& Tourism Press, 2008), hal. 78.
}

kuning biasa disandingkan dengan tembok berwarna merah karena warna merah merepresentasikan kebahagiaan dan kegembiraan. Tembok berwarna merah hanya dapat digunakan pada bangunan istana dan kuil, karena kombinasi tembok merah dan genteng kuning digunakan untuk membangkitkan suasana bahagia dan khidmat. 10

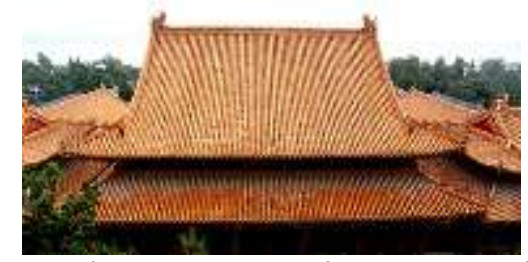

Gambar 10. Genteng bangunan tradisional Cina (Sumber:

https://wikimili.com/en/Chinese_glazed_roof_tile)

\section{DUOGONG (斗拱 dǒugǒng)}

Duogong adalah sistem pengunci tumpuan balok yang unik pada bangunan tradisional Cina. Tumpuan ini dibuat bertumpuk untuk menyangga overhang atap dan tampilannya juga menambah kesan mewah pada bangunan. Sistem pengunci duogong dapat ditemukan pada ujung atas kolom bangunan dan pertemuan antar balok pengikat struktur. Karena batasan hierarkis dalam masyarakat feodal kala itu, stuktur duogong hanya dapat ditemukan pada bangunan yang besar seperti istana dan kuil. Jumlah tumpukan pada sistem duogong juga menentukan seberapa penting bangunan itu. ${ }^{11}$

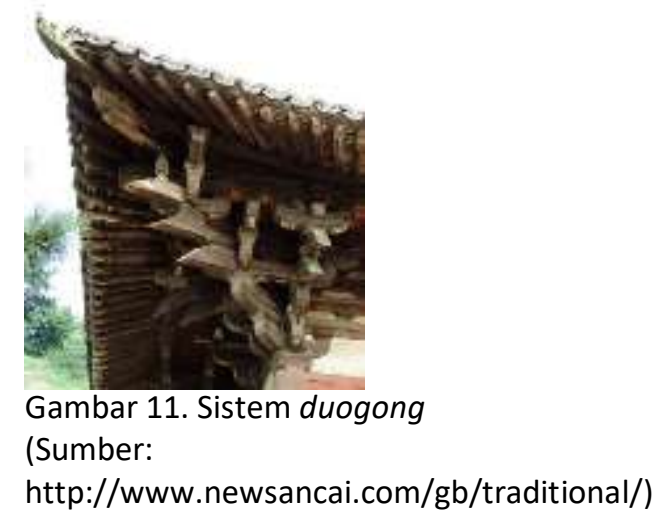

WENSHOU (吻兽 wěnshòu)

Bangunan tradisional Cina seperti istana, kuil dan rumah besar lainnya memiliki ornamen

\footnotetext{
${ }^{11}$ Du Feibao, Things Chinese, (China Travel \& Tourism Press, 2008), hal. 86.
} 
spesial berbentuk binatang pada bubungan dan jurai atapnya yang disebut dengan wenshou. Ornamen pada kedua ujung bubungan atap disebut dengan chiwen, ornamen berbentuk ikan tersebut tampak seperti sedang menggigit ujung bubungan atap sehingga disebut juga sebagai tunjishou atau monster pelahap bubungan atap. Menurut mitologi Cina, ikan tersebut adalah salah satu anak dari dewa naga yang menguasai lautan. Masyarakat Cina kuno percaya bahwa ikan tersebut dapat mengangkat ombak dan mengubahnya menjadi hujan, sehingga mereka menempatkannya di atap supaya kekuatannya dapat menurunkan hujan ketika terjadi kebakaran.

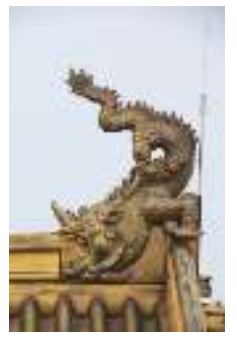

Gambar 12. Ornamen wenshou

(Sumber:

https://commons.wikimedia.org/wiki/File:Emeisha n.jinding.chiwen.jpg)

Di ujung jurai atap biasanya terdapat ornamen berbentuk barisan binatang yang ukuran dan jumlahnya tergantung kepada status pemilik bangunan tersebut. Ornamen ini biasanya berbentuk dewa yang sedang menunggang burung phoenix, naga, singa, kuda, kuda laut dan lima hewan mitologi lainnya. Hewanhewan ini juga dipercaya dapat memadamkan api. $^{12}$

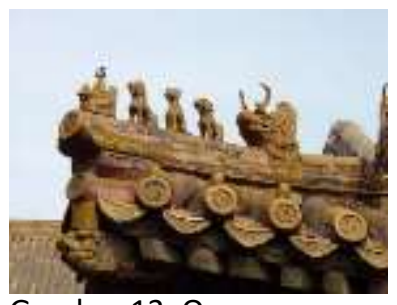

Gambar 13. Ornamen wenshou

(Sumber:

http://www.art-andarchaeology.com/china/beijing/fd05.html)

Di hampir seluruh wilayah utara, ornamenornamen tersebut terbuat dari tanah liat yang dicetak sesuai dengan bentuk hiasannya. Berbanding terbalik dengan ornamen atap wilayah utara yang sederhana, wilayah selatan memiliki ornamen atap yang lebih megah dan rumit, baik pada bangunan rumah biasa, kuil bahkan kuburan. Bentuk ornamen atap di wilayah selatan dapat dibagi menjadi 5 tipe sesuai bentuknya, yaitu:

Tipe tail feather corner (qiaojiao)

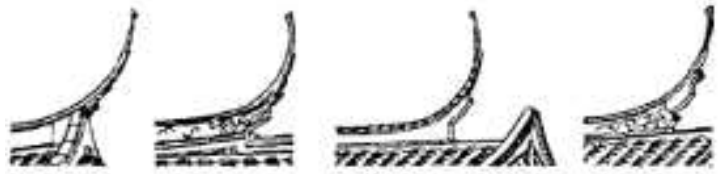

Gambar 14. Tipe tail feather corner

(Sumber: Ronald G. Knapp, China's Old Dwellings) Tipe martial ridge (wuji)
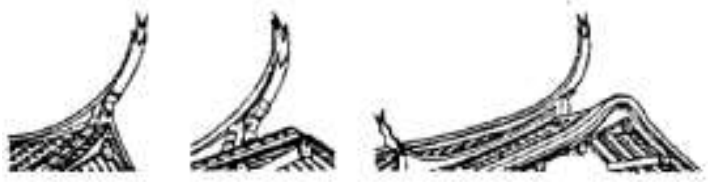

Gambar 15. Tipe martial ridge

(Sumber: Ronald G. Knapp, China's Old Dwellings) Tipe civil ridge (wenji)
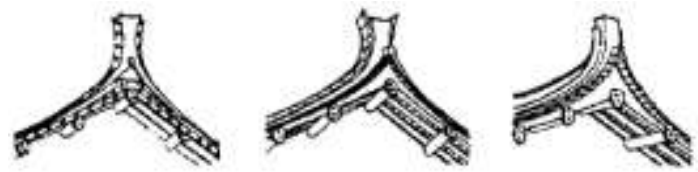

Gambar 16. Tipe civil ridge

(Sumber: Ronald G. Knapp, China's Old Dwellings) Tipe pointed tip (jianji)
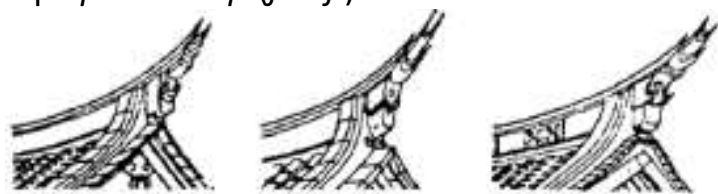

Gambar 17. Tipe pointed tip

(Sumber: Ronald G. Knapp, China's Old Dwellings) Tipe rounded ridge (yuanji)
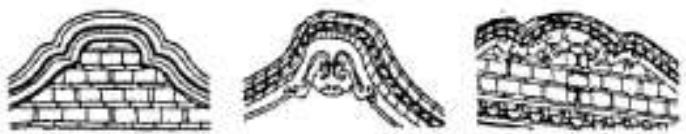

Gambar 18. Tipe rounded ridge

(Sumber: Ronald G. Knapp, China's Old Dwellings)

\section{Mahkota atap (宝顶 baoding)}

Salah satu ornamen struktur atap yaitu baoding yang artinya "harta karun di puncak", terletak di pucuk atap yang berbentuk menara segi enam atau delapan dan tidak memiliki bubungan. Biasanya ornamen ini berbentuk kendi arak, vas, pagoda, dll, yang terbuat dari

\footnotetext{
12 Du Feibao, Things Chinese, (China Travel \& Tourism Press, 2008), hal. 91.
} 
tanah liat. Ornamen ini sering kali dikelilingi oleh pahatan berbentuk naga, phoenix, bunga peony, dan binatang lainnya. Ornamen ini bukan hanya sebagai hiasan melainkan juga digunakan sebagai pelindung struktur tiang utama pada atap yang kala itu terbuat dari kayu yang menjulang tinggi sampai ke pucuk atap. $^{13}$

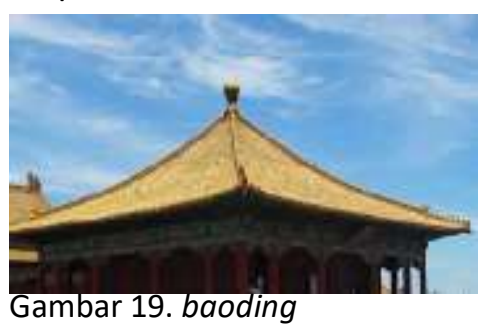

(Sumber: http://www.chinadaily.com.cn/life/201103/18/content_12191507.htm)

Penutup genteng (瓦当 wădàng)

Penutup genteng merupakan aksesoris arsitektur pada bangunan tradisional Cina sebagai dekorasi dan melindungi kaso dari hujan dan angin. Selama perkembangannya, penutup genteng berubah dari bentuk setengah lingkaran menjadi bentuk lingkaran penuh dan juga berubah dari bentuk datar menjadi ukiran. Ukiran yang terdapat pada penutup genteng bermacam-macam tergantung tema yang diterapkan, seperti tema ukiran alam, mitologi, sejarah, nama tempat, kalimat mutiara, cerita rakyat dan nama keluarga. ${ }^{14}$

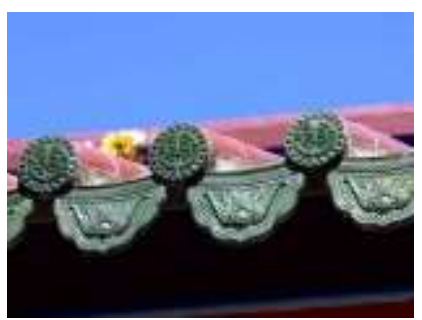

Gambar 20. wădàng

(Sumber:

http://chindonews.blogspot.com/2018/10/wadan g-atau-atap-genteng-tradisional.html)

\section{STUDI KASUS}

Sejak jaman Hindia-Belanda, Glodok dikenal sebagai pecinan terbesar di Jakarta yang kala itu bernama Batavia. Sejak abad ke-16 di Glodok telah didirikan beberapa klenteng sebagai tempat-tempat keagamaan dan kebudayaan masyarakat Tionghoa setempat. Pada tahun 1740, klenteng-klenteng di Glodok mengalami kerusakan dan pembakaran, sehingga tidak tersisa lagi peninggalan sejarah sebelum tahun $1740^{15}$. Sampai sekarang telah ada sekitar 12 klenteng yang berada di Glodok yang dibangun antara rentang abad 16 sampai dengan abad 20. Peneliti mengambil sampel beberapa klenteng di Glodok sebagai data penelitian yang akan digunakan sebagai perbandingan yang kemudian akan dianalisis tipologi arsitekturnya. Sampel ini dipilih karena merupakan klenteng besar yang ada di kawasan Glodok. Klenteng-klenteng yang dipilih sebagai studi kasus adalah:

-Klenteng Jin De Yuan

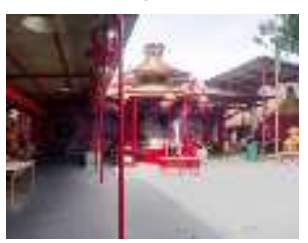

Gambar 21. Klenteng Jin De Yuan (Sumber: Dokumentasi pribadi) -Klenteng Tan Seng Ong

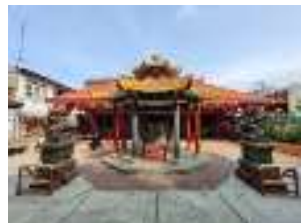

Gambar 22. Klenteng Tan Seng Ong

(Sumber: Dokumentasi pribadi)

-Klenteng Kwan Tee Bio

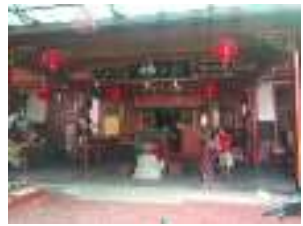

Gambar 23. Klenteng Kwan Tee Bio

(Sumber: Dokumentasi pribadi)

\footnotetext{
${ }^{15}$ Salmon, C., \& Lombard, D. (1985). Klentengklenteng masyarakat Tionghoa di Jakarta. Jakarta: Yayasan Cipta Loka Caraka.
}

\footnotetext{
${ }^{13}$ Du Feibao, Things Chinese, (China Travel \& Tourism Press, 2008), hal. 92.

${ }^{14}$ Du Feibao, Things Chinese, (China Travel \& Tourism Press, 2008), hal. 129.
} 
-Klenteng Toa Se Bio

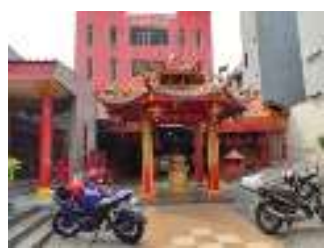

Gambar 24. Klenteng Toa Se Bio

(Sumber: Dokumentasi pribadi)

\section{ANALISA DAN PEMBAHASAN}

Tabel 1. Analisa tipologi elemen arsitektur klenteng Jin De Yuan

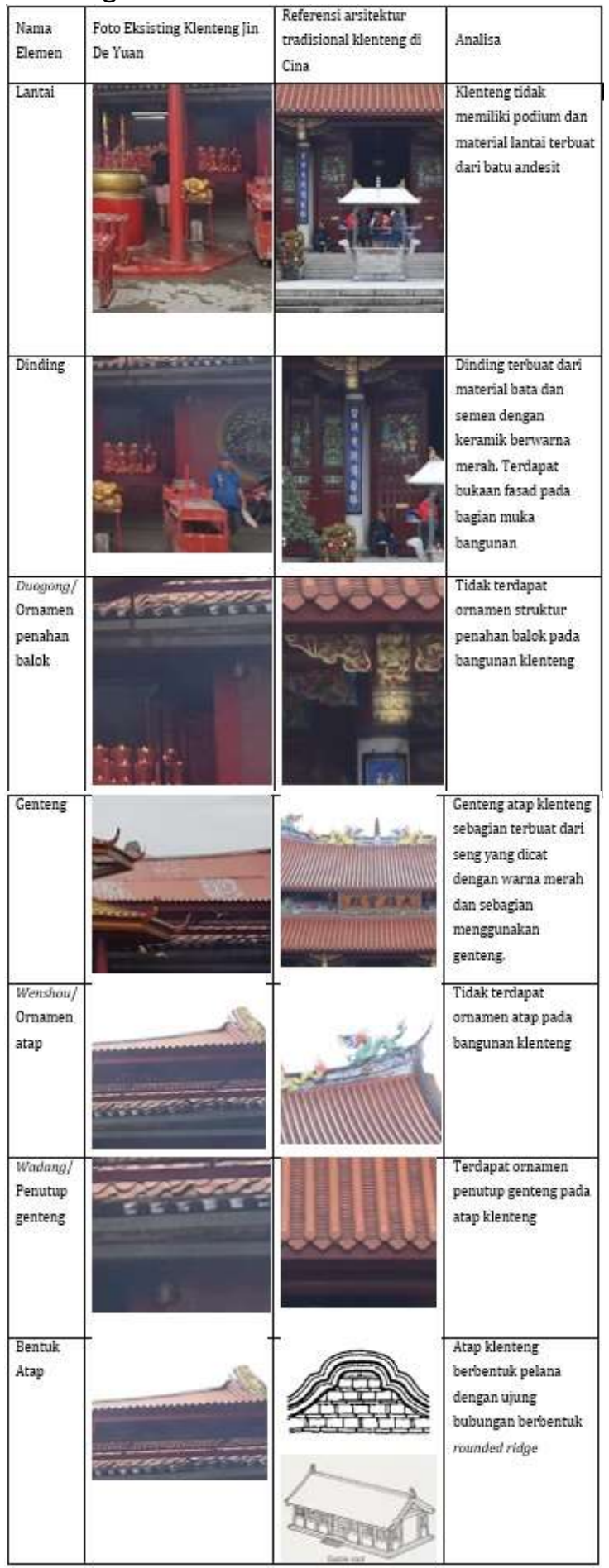

VOLUME 02 NO. 02: NOVEMBER 2020
Tabel 2. Analisa tipologi elemen arsitektur klenteng Tan Seng Ong

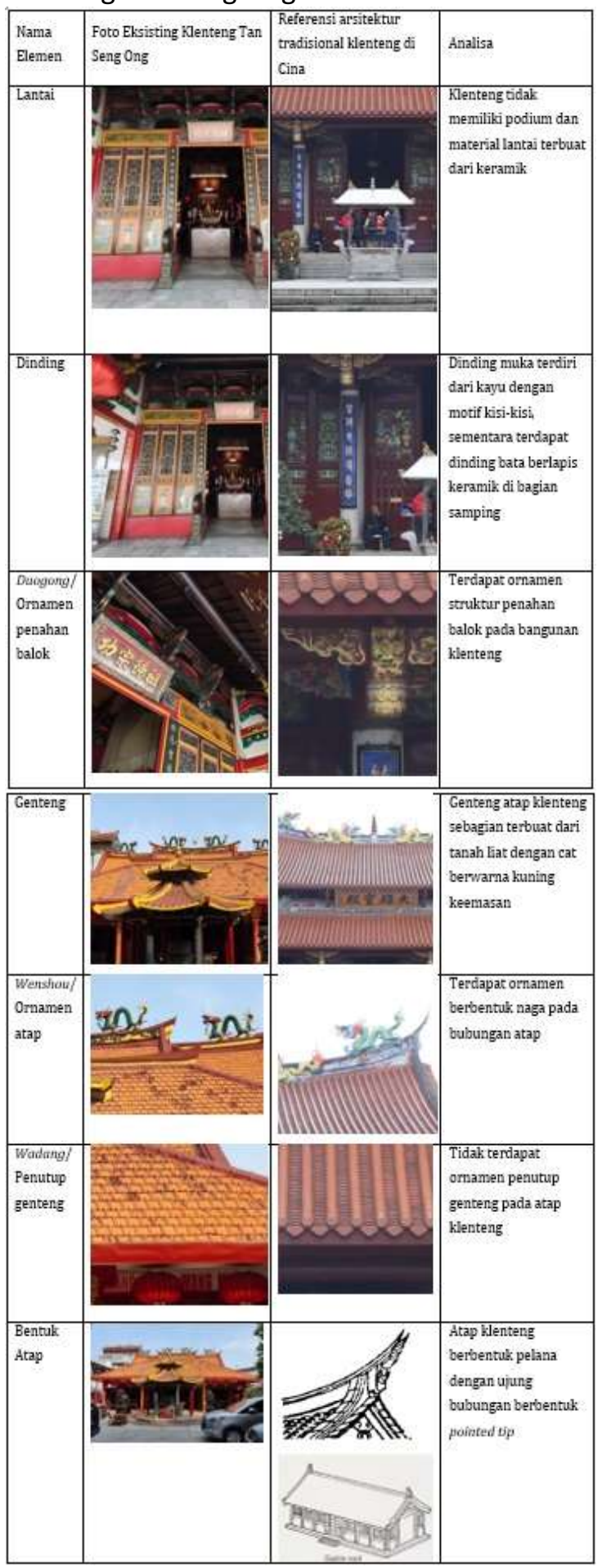


Tabel 3. Analisa tipologi elemen arsitektur klenteng Kwan Tee Bio

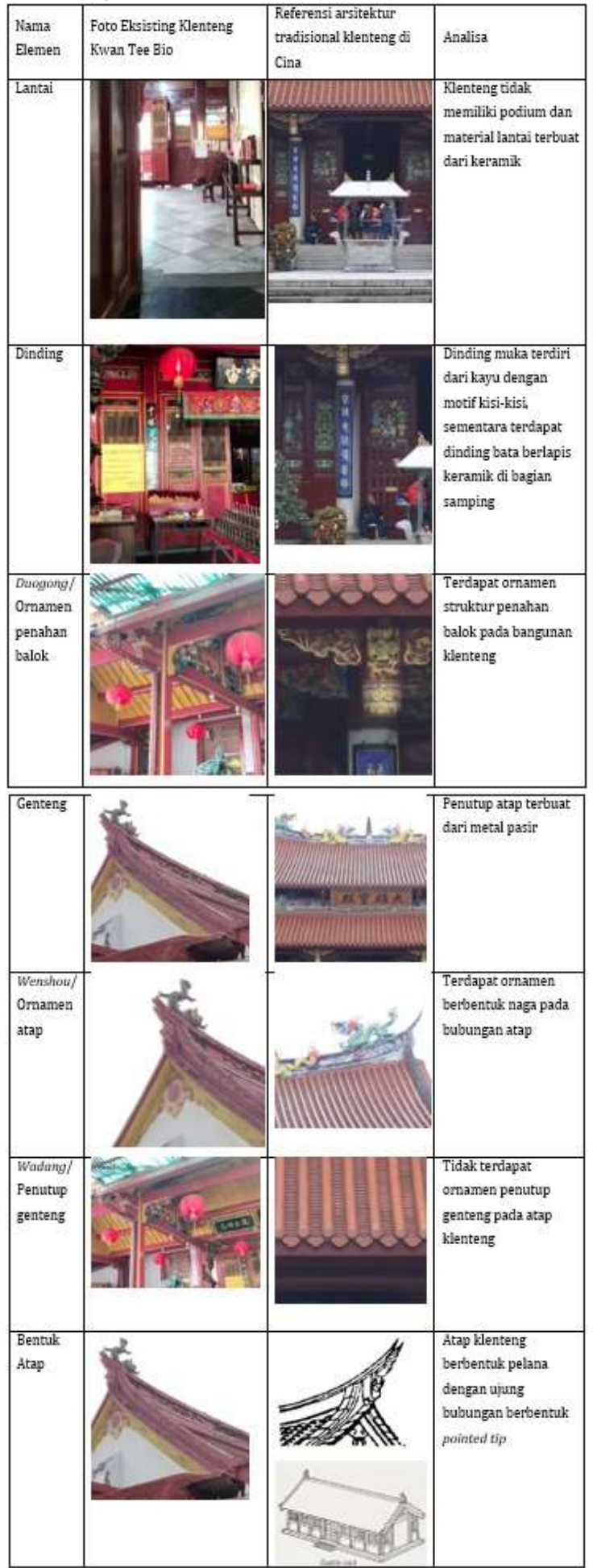

Tabel 4. Analisa tipologi elemen arsitektur klenteng Toa Se Bio

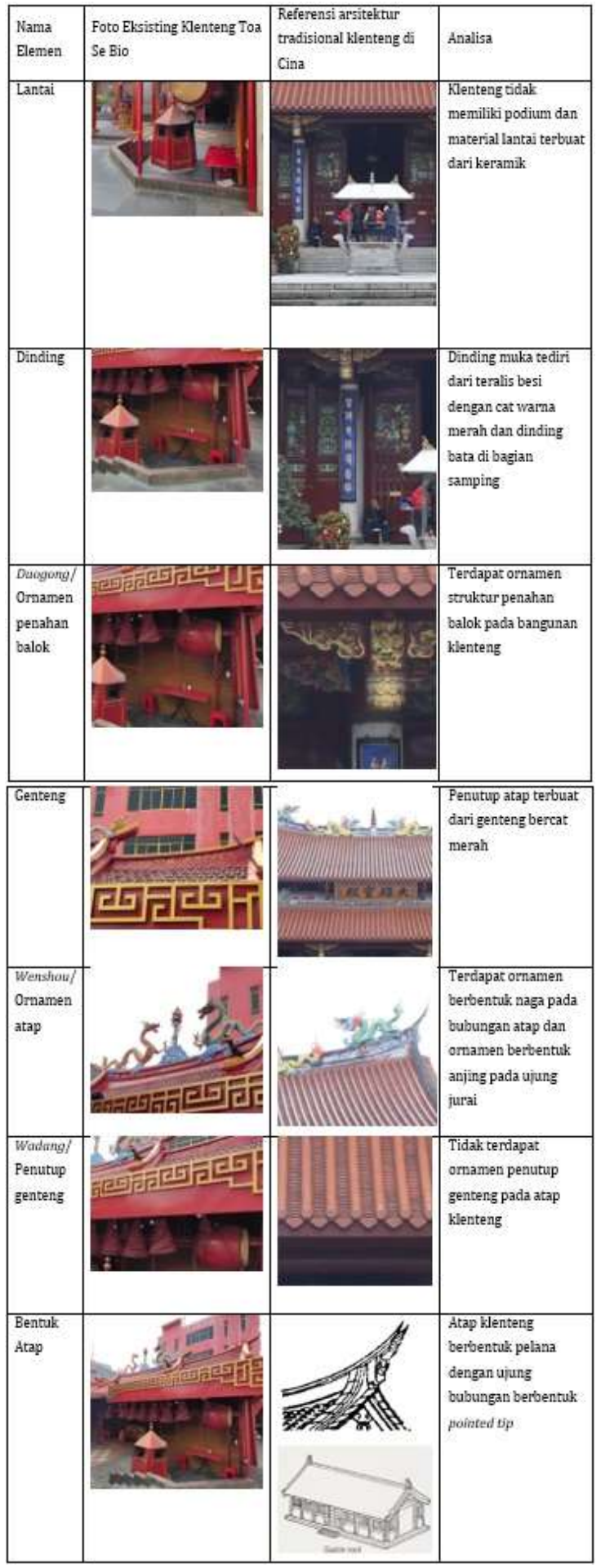




\section{KESIMPULAN}

Dari hasil penelitian ini, disimpulkan bahwa klenteng-klenteng yang diambil sebagai objek penelitian memiliki kemiripan satu sama lain. Dengan penjabaran sebagai berikut:

Lantai: Semua klenteng studi kasus tidak memiliki lantai podium. Klenteng Jin De Yuan memiliki material lantai batu andesit, sedangkan klenteng Tan Seng Ong, Kwan Tee Bio dan Toa Se Bio memiliki material lantai keramik.

Dinding: Hanya klenteng Tan Seng Ong dan Kwan Tee Bio yang memiliki kemiripan dengan bentuk dinding pada bangunan tradisional Cina yang terdiri dari kisi-kisi kayu motif.

Duogong atau ornamen penahan balok: Hanya klenteng Tan Seng Ong dan Kwan Tee Bio yang memiliki ornamen penahan balok pada bangunan klentengnya.

Genteng: Hanya klenteng Tan Seng Ong dan Toa Se Bio yang memiliki genteng tanah liat. Klenteng Jin De Yuan memiliki atap seng dan klenteng Kwan Tee Bio memiliki atap metal pasir.

Wenshou atau ornamen atap: Hanya klenteng Jin De Yuan yang tidak memiliki ornamen atap, sedangkan klenteng-klenteng studi kasus yang lain memiliki ornamen atap berbentuk naga.

Wadang atau penutup genteng: Hanya klenteng Jin De Yuan yang memiliki ornamen penutup genteng.

Bentuk atap : Semua klenteng studi kasus memiliki atap berbentuk pelana. Klenteng Jin De Yuan memiliki ujung atap berbentuk rounded ridge sedangkan klenteng-klenteng studi kasus yang lain memiliki ujung atap berbentuk pointed tip.

Dari kesimpulan di atas dapat diketahui kecocokan setiap klenteng dengan karakteristik arsitektur tradisional Cina sebagai berikut:

Klenteng Jin De Yuan memiliki kecocokan pada bentuk atap dan ornamen penutup genteng.

Klenteng Tan Seng Ong memiliki kecocokan pada ornamen pintu, duogong, material atap, wenshou dan bentuk atap.

Klenteng Kwan Tee Bio memiliki kecocokan pada ornamen pintu, duogong, wenshou dan bentuk atap.
Klenteng Toa Se Bio memiliki kecocokan pada material atap, wenshou dan bentuk atap.

Dapat disimpulkan bahwa Klenteng Tan Seng Ong memiliki kecocokan karakteristik arsitektur tradisional Cina paling banyak dibandingkan dengan ketiga klenteng lainnya. Dari karakteristik arsitektur klenteng yang dijadikan obyek penelitian dapat diketahui bahwa hampir semua klenteng tersebut memiliki material dan elemen arsitektur modern, sehingga klenteng-klenteng tersebut dapat dikategorikan sebagai bangunan peribadatan yang memiliki corak arsitektur tradisional Cina.

\section{DAFTAR PUSTAKA}

Claudin Salmon dan Denys Lombard, Klentengklenteng dan masyarakat Tionghoa di Jakarta (Jakarta: Yayasan Cipta Loka Caraka, 2003)

\section{J. L. J. F. Ezerman, Peri Hal Kelenting Koan lem "Tiao-Kak-Sie" Di Tjirebon (Weltevreden: Drukkerij Volkslectuur, 1922)}

Jakarta's historic Dharma Bhakti Temple gutted in overnight blaze, Jakarta Post, 2015-07-29

Ronald G. Knapp, China's Old Dwellings, Honolulu: University of Hawaii Press, 2000

Charis Chan, Imperial China, London, Penguin Books, 1991

Du Feibao, Things Chinese, China Travel \& Tourism Press, 2008

https://www.chinadaily.com.cn/m/shanxi/wutaish an/2015-01/08/content_19271797.htm

https://wikimili.com/en/Chinese_glazed_roof_tile

http://www.newsancai.com/gb/traditional/

https://commons.wikimedia.org/wiki/File:Emeisha n.jinding.chiwen.jpg)

http://www.art-andarchaeology.com/china/beijing/fd05.html

http://www.chinadaily.com.cn/life/201103/18/content_12191507.htm

http://chindonews.blogspot.com/2018/10/wadan g-atau-atap-genteng-tradisional.html 